\title{
The adaptive potential of newborn calves under conditions of technogenic anthropobiocenosis
}

\author{
Natalia Saenko, Vladimir Lemeshchenko, Galina Lukashik, Elena Nekhaychuk, and \\ Tatiana Skobelskaya \\ Crimean Federal University named after V. I. Vernadsky, Academician Vernadsky Avenue, 4, \\ 295007, Simferopol, Russia
}

\begin{abstract}
The article analyzes the organismal status that determines the adaptive potential of newborn calves to the conditions of technogenic anthropobiocenosis. A complex of zootechnical, clinical, hematological, morphological and statistical methods of research was used. Structural and functional changes in the fetal parts of the placentas of cows arise as a result of the aggressive impact on the mother's body of modern ecosystem conditions and determine the peculiarities of the body status of newborn calves. Determining the adaptive capabilities of one-day-old calves, including the morphology of their fetal part of the placenta, is of great importance not only for correcting the technology of growing and feeding, but also for carrying out preventive measures against infectious diseases. To create a healthy dairy herd of cows with a high degree of realization of the genetic capacities of productivity, we recommend using the developed criteria for assessing the body status of newborn calves. Keywords. Adaptive potential, newborn calves, anthropobiocenosis, organismic status, fetal parts of the placenta.
\end{abstract}

\section{Introduction}

Newborn mammals of maturonate species have a high adaptive potential from the very first minutes after birth. The analysis of the current state of dairy and meat cattle breeding shows that the incomplete realization of the adaptive, productive and reproductive capabilities of the animal body in the conditions of intensive production technology becomes an integral characteristic of the population of large domestic ungulates [1-5]. Therefore, the improvement of production technology of livestock products should be held with the account of determining the intensity of the implementation of the genotype of animals in anthropogenic ecosystems [6-9].

Under the influence of modern ecosystem conditions, first of all, placental dysfunction occurs, placental insufficiency develops, which leads to a violation of the normal functioning of the "mother - placenta - fetus" system, which is manifested in decrease in the protective and adaptive capabilities of the fetus [10-12]. The study of the fetal part of the placenta immediately after birth allows us to determine the features of the body status of the newborn animal, the presence of pathological changes in the uterine mucosa, as well as the genetic parental inferiority [13-15]. 
One should strive to create conditions that would facilitate the full implementation of the genetic potential of animals and the efficient functioning of the system "mother placenta - fetus", and to maximum satisfaction of both: production performance of livestock and biological needs of the animals $[7,8,10]$. Therefore, in ecological terms, it is necessary to move from the existing traditional concept: sick animal - diagnosis - therapy, to a new global problem: animal population - habitat - preventive measures [4].

In the conditions of environmental and technogenic pressure on the animal body, early identification of its adaptive capabilities is necessary to ensure the health and safety of calves, which is an urgent problem of modern veterinary science and practice.

The purpose of the research was establishing criteria of the organismal status that determines the adaptive potential of newborn calves to the conditions of technogenic anthropobiocenosis.

\section{Method of research}

Scientific research was carried out on the basis of the Laboratory of Veterinary Neonatology of the Department of Animal Anatomy and Physiology of the Agrotechnological Academy of the Crimean Federal University named after V.I.Vernadskiy. The object of research was the daily calves of the Red steppe breed $(n=40)$ and their fetal parts of the placenta. To analyze the adaptive capacities of the organism of newborn animals on the first day of life, the degree of prenatal osteogenesis was taken into account - indirectly by the distance between the tip of the tail (without hair cover) and the apex of the calcaneal tubercle, the length of the last rib (the distance between the dorsal end of the last rib and the frontal line, conventionally drawn through the humeral joint), the number of incisor teeth and the speed of implementation of statolocomotor acts; manifestation of unconditioned reflex acts; condition of the skin; hematological indicators; live weight at birth. Morphological study of the fetal part of the placenta, as a temporarily existing organ, rejected from the reproductive organs of a cow after the birth of offspring within 3-6 hours, makes it possible to analyze the conditions under which the fetus developed and predict its viability. In the fetal part of the placenta its mass, total area, number of cotyledons, their shape and size, the area of cotyledons, the number of stem villi, their height and thickness were determined, resulting in an intimate contact with the maternal (the mucous membrane of the uterus of the cow).

A complex of zootechnical, clinical, hematological, morphological and statistical methods of research was used.

\section{Research results}

When determining the body status of newborn calves according to the degree of adaptability to changing ecosystem conditions, they can be conventionally divided into three groups.

The calves of the first adaptive group (AG-1) have the highest survival potential, in which the distance between the tip of the tail and the apex of the calcaneal tubercle is the smallest and does not exceed $2 \mathrm{~cm}$, as well as the distance between the dorsal end of the last rib and the frontal line conventionally drawn through the humeral joint - no more than 5 $\mathrm{cm}$, which, according to our research, characterizes the optimal development of the bone system, internal organs, and, especially, immunocompetent structures (table 1). Calves of AG-1 have at least 8 incisors. Their hair is thick, shiny, and the skin fold is easily straightened. The live weight is not lower than the average for the breed, namely, it is in the range of $30-35 \mathrm{~kg}$. In newborn calves of $\mathrm{AG}-1$, the dominant of sucking and 
stato-motor activity is realized no later than 30 minutes after birth, which is also one of the indicators of prenatal development of animals, and especially of their nervous system. AG-1 calves subsequently quickly adapt to changing environmental conditions, which is emphasized by the intensive development of environmental, situational and other conditioned reflexes. The results of blood tests show that in calves after the first feeding with colostrum, the number of red blood cells is $7.10 \pm 0.06 \mathrm{~T} / 1$, and the number of white blood cells is $8.41 \pm 0.56 \mathrm{G} / 1$. The content of hemoglobin in one liter of blood does not exceed $115.00 \pm 2.45 \mathrm{~g}$. The amount of total protein in their blood serum reaches $59.80 \pm 0.76$ $\mathrm{g} / \mathrm{l}$, immune proteins only $19.80 \pm 0.66$ units of ZST, inorganic phosphorus $-1.72 \pm 0.03$ $\mathrm{mmol} / \mathrm{l}$, total calcium $-2.65 \pm 004 \mathrm{mmol} / \mathrm{l}$.

Table 1. Criteria for the organismal status of newborn calves

\begin{tabular}{|c|c|c|c|}
\hline Values & AG-1, $\mathrm{n}=8$ & AG-2, $\mathrm{n}=8$ & AG-3, $=7$ \\
\hline Live weight, kg & $32.67 \pm 1.62$ & $32.13 \pm 1.42$ & $28.50 \pm 0.79^{*}$ \\
\hline Distance from the tip of the tail to the heel, cm & $1.67 \pm 0.44$ & $2.38 \pm 0.40$ & $4.33 \pm 0.67^{* *}$ \\
\hline $\begin{array}{c}\text { Distance from the end of the last rib to the line } \\
\text { of the shoulder joint, cm }\end{array}$ & $2.83 \pm 0.18$ & $3.75 \pm 0.48$ & $5.67 \pm 0.37^{* * *}$ \\
\hline $\begin{array}{c}\text { Time of manifestation of the sucking reflex, } \\
\text { minutes }\end{array}$ & $26.67 \pm 2.31$ & $35.00 \pm 2.67^{*}$ & $48.33 \pm 5.23^{* *}$ \\
\hline $\begin{array}{c}\text { Standing posture realization time, minutes } \\
\text { Hemoglobin, g/1 }\end{array}$ & $49.17 \pm 2.97$ & $65.00 \pm 6.06^{*}$ & $72.50 \pm 7.18^{*}$ \\
\hline Red blood cells, T/1 & $115.00 \pm 2.45$ & $104.63 \pm 2.65^{*}$ & $98.33 \pm 3.67^{* * *}$ \\
\hline White blood cells, G/1 & $7.10 \pm 0.06$ & $7.00 \pm 0.07$ & $6.64 \pm 0.13^{* *}$ \\
\hline Total protein, g/l & $8.41 \pm 0.50$ & $8.64 \pm 0.34$ & $8.02 \pm 0.57$ \\
\hline Immune proteins, units of ZST & $59.80 \pm 0.76$ & $59.33 \pm 0.50$ & $57.83 \pm 0.77$ \\
\hline Inorganic phosphorus, mmol/1 & $19.80 \pm 0.66$ & $19.20 \pm 0.48$ & $18.34 \pm 1.77$ \\
\hline Total calcium, mmol/1 & $2.65 \pm 0.04$ & $2.75 \pm 0.06$ & $2.63 \pm 0.05$ \\
\hline
\end{tabular}

$*$ Acc $\leq 0.05 ; * *$ Acc $\leq 0.01 ; * *$ Acc $\leq 0.001$

When visually examined, the fetal parts of the placenta of the calves of AG-1 have a smooth, shiny, grayish-pink fetal surface. On the side of the maternal surface, yellowish cotiledons are distinguished with a size from $13 \mathrm{~cm}$ to $6 \mathrm{~cm}$ in the amount of $61.83 \pm 4.21$ pcs (table 2). The weight of the fetal parts of the placentas of calves of this group reaches $6.03 \pm 0.69 \mathrm{~kg}$, the area $-8578.00 \pm 607.59 \mathrm{~cm}^{2}$, the total area of cotiledons $-2095.69 \pm 82.03$ $\mathrm{cm}^{2}$, which is 4 times less than the area of the entire fetal part of the placenta. The villi on the cotiledons are evenly distributed and their number per $1 \mathrm{~cm}^{2}$ of cotiledon in the fetal parts of the placentas of calves AG-1 is $6.18 \pm 0.30$, and the height is within $1.18 \pm 0.16 \mathrm{~cm}$. The total number of villi is $13044.80 \pm 1000.23$, ranging from 15560.43 to 10363.89 .

Table 2. Parameters of the fetal parts of placenta of newborn calves

\begin{tabular}{|c|c|c|c|}
\hline Values & AG- $1, \mathrm{n}=8$ & AG-2, $\mathrm{n}=8$ & AG-3, $\mathrm{n}=7$ \\
\hline Weight, $\mathrm{kg}$ & $6.03 \pm 0.69$ & $6.25 \pm 0.78$ & $4.72 \pm 0.21$ \\
\hline Area, cm ${ }^{2}$ & $8578.00 \pm 607.59$ & $7936.25 \pm 568.93$ & $7073.00 \pm 523.47$ \\
\hline
\end{tabular}




\begin{tabular}{|c|c|c|c|}
\hline Number of cotyledons & $61.83 \pm 4.21$ & $61.38 \pm 2.67$ & $64.50 \pm 9.32$ \\
\hline Total area of cotiledons, $\mathrm{cm}^{2}$ & $2095.69 \pm 82.03$ & $2204.64 \pm 276.38$ & $2059.46 \pm 162.22$ \\
\hline $\begin{array}{c}\text { Number of villi per } \mathrm{cm}^{2} \\
\text { of cotyledon }\end{array}$ & $6.18 \pm 0.30$ & $5.43 \pm 0.37$ & $4.42 \pm 0.48^{* *}$ \\
\hline Thickness of the villi, cm & $0.37 \pm 0.02$ & $0.50 \pm 0.05$ & $0.56 \pm 0.65^{*}$ \\
\hline Height of the villi, cm & $1.18 \pm 0.16$ & $1.63 \pm 0.16$ & $1.70 \pm 0.07^{*}$ \\
\hline Total number of villi & $13044.80 \pm 1000.23$ & $11767.37 \pm 1069.99$ & $8863.34 \pm 666.67^{* *}$ \\
\hline
\end{tabular}

$*$ Acc $\leq 0.05 ; * *$ Acc $\leq 0.01 ; * * *$ Acc $\leq 0.001$

For fetal parts of the placenta of calves AG-1 inherent maximum parameters at the organ level of the area of cotyledons, the number of stem villi and, on the contrary, the minimum height and width of the villi.

The above parameters characterize the high adaptive potential of the body status of newborn calves and their viability. To create a healthy dairy herd of cows in the future, with a high degree of realization of the genetic capacities of productivity, it is recommended to use only such animals in reproduction.

According to the degree of realization of the genetic potential and adaptation to changing environmental conditions, the second adaptation group of calves (AG-2) is characterized by a certain decrease in the quantitative and qualitative parameters of the body status. The prenatal ontogenesis of the bone system changes to the greatest extent, as indicated by the change in the parameters of the last rib and tail. The distance between the end of the last rib and the frontal line in animals with AG-2, drawn through the humeral joint without a significant difference, increases by $24.53 \%$, and between the tip of the tail and the apex of the calcaneal tubercle - by $29.83 \%$, which indicates some underdevelopment of the bone system. However, all AG-2 calves also have 8 incisors at birth. The hair is also shiny and thick. In calves of this group, the implementation of the standing posture occurs with a significant $(p<0.05)$ delay of 15.83 minutes, as well as the sucking reflex - of 8.33 minutes. The live weight of neonatal calves of AG-2 is only $1.65 \%$ less $(p \geq 0.05)$ compared to that of the first adaptation group.

Blood tests' results, obtained after the first colostrum feeding in AG-2 calves show that the number of red blood cells decreases by only $1.41 \%(p \geq 0.05)$, while the hemoglobin content decreases significantly $(p \leq 0.01)$ - by $9.02 \%$, and the number of white blood cells, on the contrary, increases $(p \geq 0.05)$ by $2.66 \%$. The total protein content in the blood serum of newborn calves decreases by only $0.79 \%$, immune proteins - by $3.03 \%$, the amount of inorganic phosphorus - by $1.16 \%$, while the total calcium increases by $3.64 \%$. Changes in the latest indicators only tend to be more reliable.

Macroscopically, the fetal parts of the placentas of AG-2 calves differ slightly from those of AG-1. A large part of cotyledons is red with some exceptions, and, basically, in cows of the 5-th calving. Their sizes vary greatly - from $16 \mathrm{~cm}$ to $4 \mathrm{~cm}$, as well as the number - from 47 to 70 , although on average it does not differ from the indicator of the previous group. The mass of the fetal parts of the placenta is slightly larger than that of AG2 (by $3.52 \%$ ), but the area decreases by $7.49 \%$. The total area of cotiledons increases by $4.95 \%(p \geq 0.05)$, which is 3.6 times less than the area of the entire fetal part of the placenta. The number of villi per $1 \mathrm{~cm}^{2}$ of cotiledon significantly decreases by $12.14 \%(p \geq$ $0.05)$, and their thickness increases by $26.00 \%(p \leq 0.01)$, as well as their height - by $27.61 \%$. The total number of villi decreases by $9.79 \%(p \geq 0.05)$, varying from 15525.16 to 7835.44 pieces. Thus, the fetal parts of the placenta of AG-2 are characterized by a slight decrease in the area of cotiledons, the number of stem villi, but an increase in the height of the villi and their thickness. 
Calves of AG-2 are at risk for morbidity, mainly, by diseases of the gastrointestinal tract and respiratory organs. However, after recovering from the disease, the growth rate decreases even if the age-appropriate feeding diet and maintenance regime are observed. In this case, additional prevention and correction measures are needed to increase the body's resistance to aggressive environmental factors. In the absence of pastures and in the autumn-winter period, in the technology of keeping animals, we recommend to use a dosed forced movement along a terrain course or a specially equipped area.

Newborn calves, which we have assigned to the third adaptation group (AG-3), are practically non-viable. They have certain disorders of growth and development, especially of the bone system. The distance from the end of the last rib to the frontal line drawn through the humeral joint is significantly reduced by $50.09 \%(p \leq 0.001)$, and from the tip of the tail to the calcaneal tubercle - by $61.43 \%(p \leq 0.01)$. The mucous membrane of the oral cavity in calves is reddish, especially the border around the incisor teeth is highlighted. The incisor teeth are mobile, and only $65 \%$ of calves in this group have 8 incisors. The hair is not shiny, dry, hard. The elasticity of the skin is reduced. The live weight of calves is significantly lower - by $12.76 \%$ compared to that of the first adaptation group $(p<0.05)$.

Hematological indicators also highlight a significant decrease in the adaptive potential of the calves' body on the first day of life. Thus, the number of red blood cells significantly ( $p \leq 0.01$ ) decreases by $6.48 \%$, as well as hemoglobin - by $14.50 \%$, and white blood cells by only $4.64 \%(p \geq 0.05)$, compared with those of AG-1. The content of total protein in the blood serum of calves is reduced by $3.29 \%$, and immune proteins - by $7.37 \%$, inorganic phosphorus - by only $1.16 \%$, total calcium - $0.75 \%$.

The fetal parts of the placentas of calves, which are related to AG-3 by their organismal status, practically do not have yellow cotiledons. They are usually red-brown in color both in the fetal part of the placenta, located in the horn-fecundum, and in the free horn. The size of cotiledons varies greatly within even one fetal part of the placenta (from 13 to $3 \mathrm{~cm}$ ) and often have an irregular shape in the form of several cotiledons merged or separate small clusters of villi, so the total number of cotiledons increases slightly (by $4.14 \%$ ), varying from 102 to 47 pieces.

Indicators of the mass and area of the fetal parts of the placentas of calves of AG-3 are significantly lower (by $21.73 \%$ and $17.55 \%$, respectively) than those of AG-1 and vary slightly.

The number of stem villi per $1 \mathrm{~cm}^{2}$ of cotiledon in the fetal parts of the placenta of AG3 significantly decreases - by $28.48 \%(p \leq 0.001)$ relative to AG-1, while the thickness and height of the villi increase by $33.34 \%(p \leq 0.05)$ and $4.01 \%$, respectively. The total area of cotiledons differs little from that of AG-1 $\left(2059.46 \pm 162.22 \mathrm{~cm}^{2}\right)$. The total number of villi decreases by $32.02 \%(p<0.01)$, varying from 7388.14 to 11594.74 . That is, in the fetal parts of the placentas of AG-3 calves, the smallest area of cotiledons, the number of stem villi, the greatest height of the villi and their thickness are detected.

S As a rule, calves of AG-3 are not able to adapt to the conditions of the external environment and die before the end of 1-2 days or become ill with a severe form of dyspepsia, which is difficult to treat. In the future, when transferring sick animals from the maternity ward, they become ill again due to the sharp change in environmental conditions, to which they are not able to adapt adequately. In this regard, the breeding of such calves is economically unprofitable for farms with different forms of ownership, since they require intensive therapy and correction of congenital underdevelopment, their offsprings will display even less adaptive capabilities. 


\section{Conclusion}

Structural and functional changes in the fetal parts of the placentas of cows arise as a result of the aggressive impact on the mother's body of modern ecosystem conditions and determine the peculiarities of the body status of newborn calves. Determining the adaptive capabilities of one-day-old calves, including the morphology of their fetal part of the placenta, is of great importance not only for correcting the technology of growing and feeding, but also for carrying out preventive measures against infectious diseases. To create a healthy dairy herd of cows with a high degree of realization of the genetic capacities of productivity, we recommend using the developed criteria for assessing the body status of newborn calves.

\section{References}

1. J. F. Mee, J. Animals (Basel), 3(4), 1036-1057 (2013)

2. K. Mõtus, A. Viltrop, U. Emanuelson. J. Animal, 12(9),1958-1966 (2018)

3. E. Cuttance, R. Laven, Vet J., 253, 105394 (2019)

4. 4) D. Destoumieux-Garzón, P. Bonnet, C. Teplitsky, F. Criscuolo, P.-Y.Henry, D. Mazurais, P. Prunet, G. Salvat, P. Usseglio-Polatera, E. Verrier, N.C. Friggens, J.Animal, 15, 100053 (2021)

5. 5) T. Mock, J. F. Mee, M. Dettwiler, S. Rodriguez-Campos, J. Hüsler, B. Michel, I. M. Häfliger, C. Drögemüller, M. Bodmer, G. Hirsbrunner. Theriogenology, 148, 4859 (2020)

6. M. N. Alhussien, S. Tiwari, B. S. K. Panda, Y. Pandey, S. S. Lathwal, A. K. Dang. J. of Trace Elements in Medicine and Biology, 65, 126718 (2021)

7. S. M. Godden, J. E. Lombard, A. R. Woolums, 35 (3), 535-556 (2019).

8. M. Mirzaei, M. Khorvash, G. R. Ghorbani, M. Kazemi-Bonchenari, and M. H. Ghaffari, J. Dairy Sci., 100, 1086-1094 (2017)

9. A.F. Kertz, T.M. Hill, J.D. QuigleyIII,A.J. Heinrichs, J.G. Linn, J.K. Drackley. J. Dairy Sci, 100 (12), 10151-10172 (2017).

10. M. C. Windeyer, BSc, L. Gamsjäger, Vet. Clin. Food Anim., 35 (3), 557-573 (2019).

11. R. Menon, J. J. Moore, Obstet Gynecol Clin N Am, 47 (1), 147-162 (2020)

12. M.G. Lopes, A.S. Alharthi, V. Lopreiato, E. Abdel-Hamied, Y. Liang, D. N. Coleman, H. Dai, M. N. Corrêa, C. Fernandez, J. J. Loor, J. Dairy Sci, 104, 2266-2279 (2021).

13. R. L. Zur, J. C. Kingdom, W. T. Parks, S. R. Hobson, Obstet Gynecol Clin N Am, 47(1), 81-98 (2020)

14. K. L. Thornburg, J. Boone-Heinonen, A. M. Valent, Obstet Gynecol Clin N Am, 47(1), 1-15 (2020).

15. C. Gundacker, I. Ellinger, Reproductive Toxicology, 96, 273-281 (2020) 